\title{
Diagnosis of complete molar pregnancy by microsatellites in archival material
}

\author{
S A Lane, G R Taylor, B Ozols, P Quirke
}

\begin{abstract}
Aims-To develop an assay which would determine the parentage of hydatidiform molar pregnancies.

Methods-DNA was extracted from formalin fixed, paraffin wax embedded tissue from hydatidiform molar pregnancies and spontaneous abortions after separation of chorionic villi and decidua. PCR amplification of dinucleotide repeat sequences ("microsatellites") was performed using three different primers. Products were radioactively labelled and visualised by autoradiography of dried polyacrylamide gels.

Results-With informative microsatellites, diagnostic patterns of amplification were obtained. Complete moles yielded either one or two microsatellites which differed from both maternal (decidual) microsatellites. Complete mole could be excluded by all the microsatellites showing alleles identical with those in maternal DNA.
\end{abstract}

Conclusions-This technique offers a method of determining the presence of entirely paternal alleles in a molar pregnancy and thus confirming a complete hydatidiform mole.

(f Clin Pathol 1993;46:346-348)

Hydatidiform moles comprise complete and partial types, and are differentiated largely on the basis of histological diagnosis. ${ }^{1}$ Karyotypic analysis and, later, flow cytometry have shown that complete moles are largely diploid and of paternal origin with loss or inactivation of the oocyte nucleus (46 XX or $46 \mathrm{XY}$ as 46 YY appear non-viable). ${ }^{2}$ Partial moles are mostly triploid with retention of the oocyte nucleus (XXX, XXY, or XYY). ${ }^{3}$ The two paternal contributions may be homozygous or heterozygous depending on whether they result from duplication of one sperm or two separate sperm. Other groups of diploid partial moles, triploid complete moles, and tetraploid partial and complete moles have been reported. ${ }^{4}$ It has been suggested that complete moles, in particular diploid heterozygous cases, are more likely to progress to persistent trophoblastic disease. ${ }^{5}$ Cytogenetic analysis of spontaneous abortion specimens have shown that these are triploid in up to $30 \%$ of cases. ${ }^{6}$

Cytogenetic analysis determines ploidy but requires fresh tissue; it is also a lengthy proce- dure and not always successful. Paternity can also be determined by cytogenetic or VNTR PCR techniques but requires further tests on fresh tissue. Flow cytometry determines ploidy and may be performed on formalin fixed, paraffin wax embedded tissue but does not determine paternity. Southern blotting determines paternity but has similar disavantages to karyotypic analysis.

We therefore developed a simple radioactive PCR based assay to determine the parentage of molar tissue using three different microsatellite primer sets.

\section{Methods}

Four complete moles, 10 partial moles, and five spontaneous abortion specimens were taken from the archives. All material was fixed in $10 \%$ neutral buffered formol-saline overnight and routinely processed into paraffin wax. Flow cytometry had been performed on all cases: four complete moles were diploid with high hyperdiploid fractions (mean 40\%); nine partial moles were triploid and one was diploid with a low hyperdiploid fraction $(18 \%)$. The spontaneous abortions were all diploid with low hyperdiploid fractions (mean 12\%). These results are similar to those of a previously published study. ${ }^{4}$ Ten blank serial sections were cut at $5 \mu \mathrm{m}$ intervals, dewaxed in xylene, and rehydrated by passage through graded alcohols. Areas of maternal decidua and molar tissue were identified and dissected into separate Eppendorf tubes. DNA was extracted using a standard lysis solution $(0 \cdot 1 \mathrm{mg} / \mathrm{ml}$ proteinase $\mathrm{K}, 100$ $\mathrm{mM} \mathrm{NaCl}, 10 \mathrm{mM}$ TRIS-Cl, $25 \mathrm{mM}$ EDTA, $0.5 \%$ sodium dodecyl sulphate, $\mathrm{pH} 8.4$ ), incubated for 5 days at $37^{\circ} \mathrm{C}$, and extracted in phenol:chloroform then precipitated with cold ethanol. Extracted DNA samples were assayed quantitatively using a TKO-100 dedicated minifluorometer (Hoefer Scientific Instruments, San Francisco, USA).

Extracted DNA solution $(1 \mu \mathrm{l})$ was amplified in a $50 \mu \mathrm{l}$ PCR reaction using the three primer sets to microsatellite sequences at $21 \mathrm{q} \cdot 22,{ }^{7} 19 \mathrm{q} \cdot 13^{8}$ and $5 \mathrm{q} \cdot 21 .{ }^{9}$ These are highly polymorphic in the general population but, without maternal and paternal blood samples for direct comparison, at least three primer sets are needed to give a sufficient probability that identical maternal and fetal microsatellite patterns are not caused by chance alone. (The polymorphism information content (PIC) for the three primers is $0.80,0.79$, and 0.70 respectively; combined PIC of $>$ 


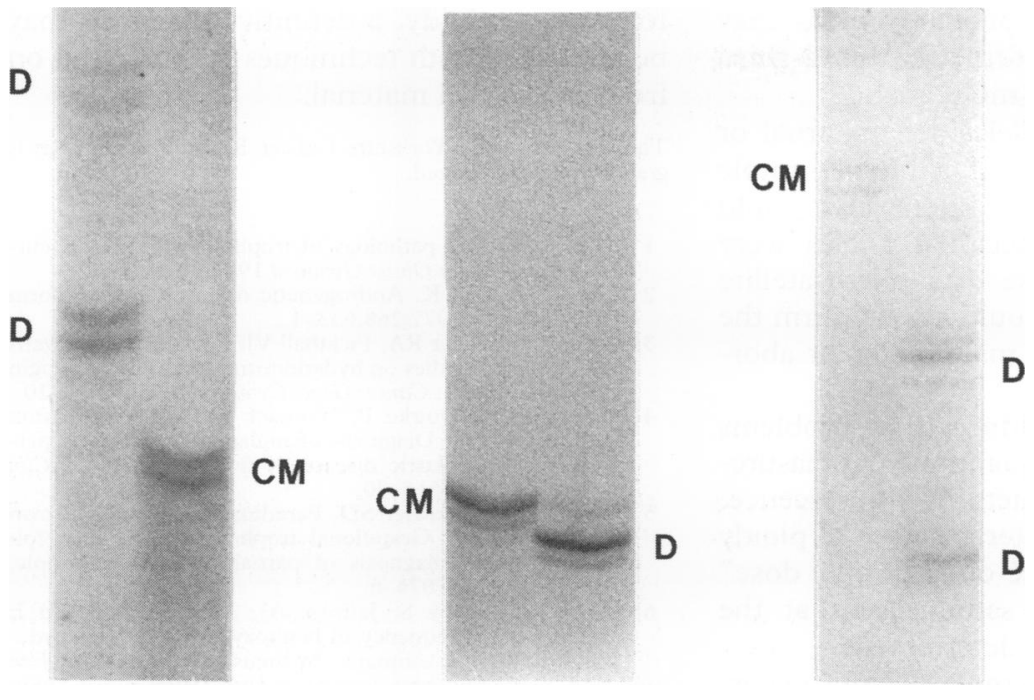

Figure 1 Products from the complete molar tissue (CM) differ from those of maternal decidua (D) with all three primer sets.

$0 \cdot 97 .^{7-9}$ ) Trace amounts of ${ }^{35} \mathrm{~S}$ labelled ATP were added to the PCR mixture to label the amplified products. In each reaction a negative (distilled water) and positive (normal human DNA) control were included in place of test DNA. The PCR mix comprised 50 $\mathrm{mM} \mathrm{KCl}, 10 \mathrm{mM}$ TRIS, $1.5 \mathrm{mM} \mathrm{Mg} \mathrm{Cl}$, $0.01 \%$ gelatin, $0.4 \mathrm{mM}$ each of dTTP, dCTP, and dGTP, $0.2 \mathrm{mM}$ dATP, $0 \cdot 1 \mu \mathrm{M}$ of each oligonucleotide primer, $1.5 \mathrm{U}$ superTaq polymerase $\mathrm{pH} 8.3$ (HT Biotechnology Ltd).

The thermal cycling sequence was as follows: denaturing at $95^{\circ} \mathrm{C}$ for 5 minutes, 35 cycles at $95^{\circ} \mathrm{C}$ for 30 seconds and $58^{\circ} \mathrm{C}$ for 2 minutes, final extension at $72^{\circ} \mathrm{C}$ for 5 minutes.

Products were denatured at $95^{\circ} \mathrm{C}$ for 3 minutes and electrophoresed at $2000 \mathrm{~V}$ in an $8 \%$ polyacrylamide gel in TBE (45 mM TRIS-borate, $1 \mathrm{mM}$ EDTA). The gels were dried and autoradiography performed using high affinity Kodak $x$ ray film for 3 to 10 days.

\section{Results}

COMPLETE MOLES

PCR products were generated with all three primer sets in all four cases. In three cases either one or two amplified products were generated with each primer set from the molar tissue which differed from the products generated from maternal decidua (fig 1). In the other case two primer sets yielded a diagnostic result of non-maternal bands; the remaining primer set gave two identical products with both molar and decidual tissue.

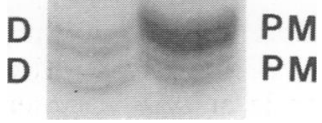

Figure 2 The staining intensity of one product from a partial mole (PM) is greater than the other and could indicate the presence of an identical third allele.
Six cases gave PCR products with all three primer sets, one with two sets, and three did not generate any products. In the first seven cases the molar and decidual tissue of one amplified product was identical (indicating the maternal band; the other product was different (indicating the paternal band) with at least one primer set. The other primer sets gave two identical products with both molar and decidual tissue. None of the cases showed both products to be inconsistent with maternal origin as seen in the complete moles.

A third PCR product was not separately identified in these cases, but the staining intensity of one product was often greater than the other (fig 2).

\section{SPONTANEOUS ABORTIONS}

All five cases generated PCR products with all three primer sets. All five showed findings similar to those of the partial moles of a single or both products, overlapping with those of the maternal decidua. One case showed products identical with those of the decidua with all three primers.

With increasing cycle number there were additional bands formed, of the kind commonly seen with dinucleotide microsatellites. After optimisation this laddering effect, however, did not prevent genotypes from being assigned.

\section{Discussion}

These results provide a qualitative method of determining paternal or maternal origin of samples of hydatidiform molar tissue, as compared with maternal decidual tissue from archival material.

Using our panel of three microsatellite primers, an unambiguous result was found in all four cases of complete mole; complete moles yielded either a single or two microsatellite bands which differed from both maternal microsatellites with at least two primer sets. This pattern was not seen with the partial moles or spontaneous abortion tissues. A similar finding with complete moles was reported by Fukuyama et al ${ }^{10}$ using the VNTR primer Apo2B on fresh molar tissue. Two of four of our cases, however, gave equivocal results with one primer and it is possible that, using only one primer, cases of complete mole may have been missed.

In the cases of partial mole only two alleles were identified, one of which was the same as a maternal allele: this did not exclude or confirm partial molar pregnancy, and a similar pattern was seen with four of five of the spontaneous abortion samples (table).

Microsatellite alleles may be as close as two base pairs from each other. Band laddering made readings of genotypes with allele sizes which were very close to each other problematical. In some cases of partial mole one allele

Number of alleles present which were also present in maternal (decidual) tissue

\begin{tabular}{llll}
\hline $\begin{array}{l}\text { No of identical alleles present } \\
\text { in molar and } \\
\text { maternal tissue }\end{array}$ & & & \\
\hline & 0 & 1 & $2^{\star}$ \\
Complete moles $(\mathrm{n}=5)$ & 5 & 0 & 0 \\
Partial moles $(\mathrm{n}=7)$ & 0 & 7 & 0 \\
Spontaneous abortions $(\mathrm{n}=5)$ & 0 & 4 & 1 \\
\hline
\end{tabular}

* All three primer sets provided two identical alleles with those of the maternal decidua. 
showed a much greater intensity. This may indicate the presence of the expected third allele in a triploid partial mole.

Determining which alleles are maternal or paternal would be easier if a blood sample was available from each parent and could confirm that the non-decidual alleles were indeed paternal. The use of a microsatellite on the $\mathrm{Y}$ chromosome would also confirm the paternal contribution in male moles or abortuses.

Work is ongoing to address these problems and to permit actual quantitative measurement of the PCR products by fluorescence. This will result in the determination of ploidy and the possible presence of a "double dose" of one allele from the same parent at the same time as paternity is determined.

Three cases of partial mole did not generate PCR products with any of the three primer sets. This may reflect the limited amount of molar tissue available in a case of partial mole which is a patchy process, although failure of PCR on archival material has been reported before.

In conclusion, this technique offers a confirmation of complete molar pregnancy with the presence of entirely paternal alleles in the molar tissue. Combined with flow cytometry to measure ploidy, a definitive diagnosis may be given and both techniques may be used on fresh or archival material.

The support of the Yorkshire Cancer Research Campaign is gratefully acknowledged.

1 Elston CW. The pathology of trophoblastic disease: current status. Clin Obstet Gynaecol 1984;2:135-52.

2 Kajii T, Ohama K. Androgenetic origin of hydatidiform mole. Nature 1977;268:633-4.

3 Lawler SD, Fisher RA, Pickthall VJ, Povey S, Wyn Evan $M$. Genetic studies on hydatidiform moles. I. The origin of partial moles. Cancer Genet Cytogenet 1982;5:309-20.

4 Hemming JD, Quirke P, Womack C, Wells M, Elston $C W$, Bird CC Dian sistent trophoblastic disease by flow cytometry. $\mathcal{f}$ Clin Pathol 1987;40:615-20.

5 Bagshawe KD, Lawler SD, Paradinas FJ, Dent J, Brown P, Boxer GM. Gestational trophoblastic tumours following initial diagnosis of partial hydatidiform mole. Lancet 1990;ii: 1074-6.

6 Fisher RA, Povey S, Jeffreys AJ, Martin CA, Patel I, Lawler SD. Frequency of heterozygous complete hydatidiform moles, estimated by locus-specific minisatellite and Y chromosome-specific probes. Hum Genet 1989, 82:259-63.

7 Guo Z, Sharma V, Patterson D, Litt M. TG repeat polymorphism at the D21S 167 locus. Nucleic Acids Res 1990;18:4967.

8 Weber JL, May PE. Abundant class of human DNA polymorphisms which can be typed using the polymerase morphisms which can be typed using the polym

9 Breukel C, Tops C, van Leeuwen C, et al. CA repeat polymorphism at the DS 582 locus proximal to adenomatous polyposis coli (APC). Nucleic Acids Res 1991;19: matous

10 Fukuyama R, Takata $M$, Kudoh J, Sakai K, Tamura S, Shimizu N. DNA diagnosis of hydatidiform mole using the polymerase chain reaction. Hum Genet 1991;87: 216-18. 